\title{
PROBIOTICS IN AQUACULTURE AND THEIR APPLICATIONS AGAINST PATHOGENIC BACTERIA
}

\author{
M. ALAGAWANY ${ }^{*}$, M. T. EL-SAADONY² AND M. R. FARAG ${ }^{3}$ \\ ${ }^{1}$ Poultry Department, Faculty of Agriculture, Zagazig University, Zagazig-44511, Egypt \\ ${ }^{2}$ Department of Agricultural Microbiology, Faculty of Agriculture, Zagazig University, \\ Zagazig - 44511, Egypt \\ ${ }^{3}$ Forensic Medicine and Toxicology, Faculty of Veterinary Medicine, Zagazig University, \\ Zagazig- 44511, Egypt
}

\begin{abstract}
Probiotics play important role in improving the public health by enhancing the internal microbial balance. Probiotic bacteria produce siderophores, bacteriocins, lysozymes, hydrogen peroxides and proteases, which can inhibit pathogenic bacteria. Also, some beneficial bacteria provide amino acids, vitamins, enzymes and fatty acids. Bacillus subtilis, Aeromonas spp., Bacteroidaceae, Lactobacillus plantarum, Clostridium spp., and Staphylococcus sp. produce amylase, but B. subtilis and Staphylococcus sp., L. plantarum produce protease, while L. plantarum, B. subtilis, and Staphylococcus sp. produce cellulase. In aquaculture, probiotics have different health benefits and play key roles in increasing growth rate, improving disease resistance, immunity, gut microbiota, and in enhancement of epithelial barrier integrity. Furthermore, the uses of probiotics additives in fish diets could minimize the side effects of antibiotic growth promoters. Promoting the application of probiotics for fish would help improve the production, reproduction and feed efficiency and, therefore, safeguard consumer health as well. This article reviewed the definitions, probiotic use in fish rations against pathogens and potential uses of probiotics in aquaculture.
\end{abstract}

Key words: Fish, Health, Nutrition, Pathogenic bacteria, Probiotics

\section{Introduction}

Aquaculture has been found to be a key cause of antibiotic contamination in areas where antibiotics are used (Rico et al., 2014). One possible solution to the problems of bioaccumulation and antibiotic resistance that aquaculture faces, is the use of nutraceuticals and feed additives (Abd El-Hack et al., 2016; Alagawany et al., 2020 a,b,c; 2021). The term nutraceutical is a compound word that combines nutrition and pharmaceutical. Therefore, nutraceuticals can be defined as "substances that have physiological benefits or provide protection against chronic diseases" (Hamid et al., 2014). There are different types of nutraceuticals, like phytochemicals and dietary supplements, and one important category is tailored food (Hamid et al., 2014; Abdel-Latif et al., 2020; Naiel et al., 2020a,b; Mahmoud et al., 2021). Tailored foods can be defined as "any food or ingredient that has a positive effect on an individual's health, performance, or state of mind" (Hardy, 2000). There are different types of functional foods. Prebiotics and probiotics are two emerging types of feed additives that have shown promise for use in fish production (Schmidt et al., 2017; Wang et al., 2019; Elgeddawy et al., 2020; López Nadal et al., 2020; Ring ø et al., 2020; Sharif et al., 2021). 
Probiotics were originally defined as "A live microbial feed supplement which beneficially affects the host animal by improving its intestinal microbial balance" (Fuller, 1989). A more modern definition is "Live microorganisms which, when administered in adequate amounts confer a health benefit on the host," (FAO \& WHO, 2006; Alagawany et al., 2016, 2018; Soomro et al., 2019). Probiotics work by supporting and complementing the host's natural gut microbiota and they can accomplish this through a variety of means, and safeguard health of fish and aquaculture species from various aspects including of potential antimicrobial and biocontrol agents (Bentzon-Tilia et al., 2016; Zorriehzahra et al., 2016; Banerjee and Ray, 2017; Hoseinifar et al., 2018; Noor et al., 2020; Ring $\varnothing$ et al., 2020). The present review describes definitions of probiotics and use of probiotic in aquaculture as well as its use against pathogenic bacteria in fish aquaculture.

\section{Definitions and use of probiotics in fish production}

In literature, there are many variations in the definition of probiotics and most of them are specific to a health benefit conferred on the gut of the host (Gatesoupe, 1999). Historically, many of these definitions are associated with the grampositive lactic acid bacteria (LAB) administered to humans and terrestrial animals. The increasing interest in farmed fish and shellfish has also led to investigations of potential probiotic use in the aquaculture industry. The use of probiotics in intensive larviculture of various marine fishes could be a promising future strategy, as indicated by evidence-based approaches (Tarnecki et al., 2019; Wang et al., 2019; Kuebutornye et al., 2020; Noor et al., 2020; Ringø et al., 2020).

Bacilli have been observed to improve the survival of reared shrimp and control the luminous Vibrio spp. (Moriarty, 1998). Bacillus sp. can also protect the live-feed (Artemia) and increase survival by reducing the activity of Vibrio campbellii and enhancing the innate immune response of the artemia larvae (Niu et al., 2014). Defoirdt et al. (2011) isolated Bacillus spp. from white leg shrimp and European sea bass, which could degrade $\mathrm{N}$-acylhomoserine lactones (AHL). Degrading the AHLs can disrupt the Quorum Sensing (QS) modulated phenotypes such as virulence. Quorum quenching Bacillus sp. QSI-1 reduced pathogenicity of $A$. hydrophila in zebrafish (Danio rerio) and thereby improved the survival rate (Chu et al., 2015). It will not necessarily decrease the pathogen load and an imbalance might still allow the opportunists to gain dominance.

While LAB strains seem somewhat promising as probiotics in aquaculture (Zorriehzahra et al., 2016; Kuebutornye et al., 2020), it is important to assess both strengths and weaknesses. If they are to be used as probiotics in larviculture they may not serve their full purpose in the early fish-life stages because the gastrointestinal tract is not fully developed and the microbiome inside the larvae is transient- being an extension of the microbiota in the tank (Bentzon-Tilia et al., 2016)- which is not (yet) dominated by Firmicutes. Hence, other species that are adapted to and act in the marine environment are likely more suitable at this stage. Proteobacteria such as Pseudomonas spp., Shewanella spp., Vibrio spp., and members of the Roseobacter group have been proposed as non-LAB probiotics (Tapia-Paniagua et al., 2014; Porsby and Gram, 2016; Dittmann et al., 2017), especially due to their antagonism against pathogens. Gram et al. (2001) investigated the probiotic potential of Pseudomonas fluorescens strain AH2 against $V$. anguillarum and $A$. salmonicida. The growth of both pathogens was inhibited in vitro by $P$. fluorescens $\mathrm{AH} 2$ and the effect was increased during iron-limited growth conditions. This effect indicated that part of the probiotic effect could be due to iron competition (siderophores), although the experimental conditions did not allow for an exact determination of this 
(Gram et al., 1999). While the probiotic Pseudomonas could protect rainbow trout against vibriosis (Gram et al., 1999), furunculosis caused by A. salmonicida in Atlantic salmon (Salmo salar L.) was unaffected by the probiotic treatment (Gram et al., 2001). Hence, it is impossible to predict a "good" probiotic insitu based on in vitro experimental results; in vivo trials of probiotic candidates against different target pathogens in a variety of fish systems are required to determine their spectrum of activity.

\section{Use of probiotic against pathogenic bacteria in fish aquaculture}

The organisms that have the potential to improve the health or survival of farmed aquatic species are more diverse and greater in number than those used for human nutrition (i.e., mostly the lactic acid bacteria) and terrestrial veterinary medicine. Thus, a wide range of Gram-positive and Gramnegative bacteria, bacteriophages, unicellular algae, and yeasts as well as beneficial isolates from humans [L. rhamnosus (Nikoskelainen et al., 2003) and L. plantarum (Picchietti et al., 2007)] and terrestrial animals [C. butyricum from the intestine of healthy chickens (Pan et al., 2008)] has been evaluated for use in aquaculture (Zorriehzahra et al., 2016; Soliman et al., 2019; Kuebutornye et al., 2020; Ring $\varnothing$ et al., 2020;Z aczek et al., 2020). This is because, the mode of action of probiotics is not similar and shows variations in efficacy, suggesting that one probiotic could not be used universally for all fish species to control single or multiple diseases. Among the Gram-positive bacteria, Bacillus species (such asB. subtilis) is the best evaluated genus for use in fish and shellfish farming, followed by various species of Lactobacillus (L. plantarum, L. rhamnosus). Other genera include Arthrobacter, Brevibacillus, Brochothrix, Clostridium, Carnobacterium, Enterococcus, Kocuria, Lactococcus, Leuconostoc, Microbacterium, Micro-coccus, Pediococcus, Rhodococcus, Streptococcus, Streptomyces, Vagococcus and
Weissella. Although potential safety concerns due to the acquisition of virulence genes by horizontal gene transfer could be an issue in using Gram-negative bacteria, yet genera of fish or shellfish pathogens, such as Aeromonas, Pseudomonas and Vibrio, have been evaluated and found to be beneficial to aquatic hosts. Probiotics of these taxa include A. hydrophila, A. sobria, P. fluorescens, P. chlororaphis, $V$. alginolyticu and $V$. proteolyticus. Amongst other genera, Agarivorans, Alteromonas, B. dellovibrio, Burkholderia, Citrobacter, Enterobacter, Neptunomonas, Phaeobacter, Pseudoalte-romonas, Rhodo-pseudomonas, Roseobacter, Shewanella, Synechococcus, Thalassobacter and Zooshikella have also demonstrated usefulness (Hai and Fotedar, 2009; Alagawany et al., 2020 a,b,c; 2021). For example, dietary Bacillus and A. sobria were effective in controlling multiple bacteria, such as $V$. anguillarum, V. ordalii, La. garvieae, A. salmonicida, S. iniae and $Y$. ruckeri, in rainbow trout. Moreover, the efficacy of Carnobacterium sp. in reducing diseases caused by A. salmonicida, V. ordalii and Y. ruckeri in salmonids has been studied. Improved resistance to $V$. anguillarum in cod fry was also reported after the addition of $C$. divergens (Gildberg and Mikkelsen, 1998). The addition of strain JE-34 (Zooshikella sp.) in diets enhanced the innate immune response and disease resistance in olive flounder (Paralichythys olivaceus) against S. iniae (Kim et al., 2010). When applied in water, a mixture of $L$. plantarum, L. rhamnosus and $L$. salivarius led to enhanced survival of $P$. pelagicus larvae (Talpur et al., 2012). Moreover, P. chlororaphis induced disease resistance in perch against $A$. sobria (Gobeli et al., 2009). In shellfish, B. subtilis E20 demonstrated effectiveness in controlling $V$. alginolyticus infection in white shrimp; probiotic supplements at concentrations of $10^{6}$, $10^{7}$, and $10^{8} \mathrm{cfu} / \mathrm{kg}$ significantly increased survival rates by $13.3 \%, 16.7 \%$, and $20 \%$ respectively, compared to the control group fed 
no probiotic (Tseng et al., 2009). Moreover, feeding with probiotic Synechococcus increased the survival of shrimp ( $P$. monodon) post-larvae following a challenge with $V$. harveyi (Preetha et al., 2007). Separately, Pseudoalteromonas protected scallop larvae against infection with $V$. splendidus and Pacific oyster against $V$. coralliilyticus (Kesarcodi-Watson et al., 2012). Arthrobacter $p$ XE-7 significantly enhanced the immune parameters in white shrimp and, at the same time, significantly reduced host mortality due to $V$. parahaemolyticus (Li et al., 2012).

Bacteriophages from the viral families Myoviridae and Podoviridae, isolated from diseased ayu (Plecoglossus altivelis) and administered orally, have proved effective at reducing $P$. plecoglossicida infections in medicated fish and numbers of the pathogen in water (Park et al., 2000). Moreover, administration of a lytic phage cocktail $\varphi S t 2$ and $\varphi$ Grn1 (obtained from V. alginolyticus) directly to live prey artemia (Artemia salina) cultures led to a $93 \%$ decrease in presumptive Vibrio load after four hours of treatment, suggesting that the Vibrio population responsible for disease outbreaks in the marine larviculture system can be potentially eliminated by phage therapy (Kalatzis et al., 2016). Microalgae such as Dunaliella salina, D. tertiolecta, Isochrysis galbana, Phaeodactylum tricornutum and Tetraselmis suecica are also reported to promote growth, survival, and health of marine larvae (Supamattaya et al., 2005; Marques et al., 2006). Enhanced protection of gnotobiotic artemia against $V$. campbellii and $V$. proteolyticus was also conferred by the unicellular algal species D. tertiolecta (Marques et al., 2006). The freshwater green microalga Parietochloris incisa, which is rich in arachidonic acid, was reported to have health benefits in the guppy (Poecilia reticulata) when administered as a dietary supplement for a period of 14 days (Dagar et al., 2009).
The use of yeast holds great promise as a probiotic in aquaculture, yet this eukaryotic microbial group has received little attention. Different yeast products, such as cells and beta-glucan of Saccharomyces cerevisiae, Phaffia rhodozyma, and live S. exiguous containing xeaxanthin pigment (HPPR1), had a positive effect on juvenile $P$. vannamei, leading to better survival against $V$. harveyi (Scholz et al., 1999). Oral administration of a polyamine (spermine and spermidine)-producing yeast, Deba-ryomyces hansenii, improved survivability but reduced the growth of European sea bass (Dicentrarchus labrax) larvae (Tovar et al., 2002). A mixture of yeasts (isolates SS1, AY1) and bacteria (isolate SY9), which was added to dry feed at $10^{7} \mathrm{cfu} / \mathrm{g}$ and fed to abalone (Haliotismidae) for 14 days, led to $62 \%$ survival after challenge with $V$. anguillarum compared to $25 \%$ survival of the controls (Macey and Coyne, 2005). Also, marine yeast (Yarrowiali polytica) supplementation (with microalgae) was effective in improving the survival and growth of juvenile pearl oyster, Pinctada mazatlanica (Aguilar-Macias et al., 2010). Indeed, S. cerevisiae has been documented as a probiotic for catla (Catla catla) (Mohanty et al., 1996), hybrid striped bass (Moronechrysopsx M. saxatilis) (Li and Gatlin, 2004), flounder (Taoka et al., 2006a), Nile tilapia (Taoka et al., 2006b), and common carp (Cyprinus carpio) (Faramarzi et al., 2011).

\section{Conclusion}

Probiotics as feed additives aid proper digestion of feed and make the nutrients available for faster growth and higher production. Immune functions can also be enhanced by the addition of probiotics to several infectious diseases of fish can be countered by adding probiotics to fish diets, but proper selection of the strain is needed for achieving optimal impact. Furthermore, probiotics can be used as beneficial bacteria to eliminate pathogens. Potentially, probiotics help to enhance nutrient digestibility, growth curve, productivity, feed efficiency and the health of fish. Future studies could generate more information and experience in order to understand probiotic sources and strains and their exact mode of action, as well as to explore their applications in fish production. 


\section{REFERENCES}

Abd El-Hack M, Alagawany M, Farag MR, Tiwari R, Kartixk K et al., 2016. Beneficial impacts of thymol essential oil on health and production of animals, fish and poultry: A review. J Essent Oil Res, 28(5): 365-382, doi: 10.1080/ 10412905.2016.1153002

Abdel-Latif HMR, Soliman A, Sewilam H, Almir R, Doan HV et al., 2020. The influence of raffinose on the growth performance, oxidative status, and immunity in Nile tilapia (Oreochromis niloticus). Aquacult Rep, 18: 100457, doi: 10.1016/j.aqrep.2020.100457

Aguilar-Macias OL, Ojeda-Ramirez JJ, CampaCordova AI and Saucedo PE, 2010. Evaluation of natural and commercial probiotics for improving growth and survival of the pearl oyster, Pinctada mazatlanica, during late hatchery and early field culturing. J World Aquac Soc, 41(3): 447-454, doi: 10.1111/ j.1749-7345.2010. 00386.x

Alagawany M , Farag MR, Salah AS and Mahmoud MA, 2020a. The role of oregano herb and its derivatives as immunomodulators in fish. Rev Aquac, 12(4): 2481-2492, doi: 10.1111/ raq. 12453

Alagawany M, Abd El-Hack ME, Farag MR, Shaheen HM, Abdel-Latif MA et al., 2020b. The applications of Origanum vulgare and its derivatives in human, ruminant and fish nutrition - A review. Ann Anim Sci, 20(2): 389-407, doi: 10.2478/aoas-2020-0004

Alagawany M, Farag MR, Abdelnour SA, Dawood MAO, Elnesr SS et al., 2021. Curcumin and its different forms: A review on fish nutrition. Aquaculture, 532: 736030, doi: 10.1016/ j.aquaculture. 2020.736030

Alagawany M, Abd El-Hack ME, Farag MR, Sachan S, Karthik K et al., 2018. The use of probiotics as eco-friendly alternatives for antibiotics in poultry nutrition. Environ Sci Pollut Res, 25(11): 10611-10618, doi: 10.1007/s11356018-1687-x

Alagawany M, Farag MR, Abdelnour SA and Elnesr SS, 2020c. A review on the beneficial effect of thymol on health and production of fish. Rev Aquac, 13(1), doi: 10.1111/RAQ.12490

Alagawany M, Abd El-Hack ME, Arif M and Ashour EA, 2016. Individual and combined effects of crude protein, methionine, and probiotic levels on laying hen productive performance and nitrogen pollution in the manure. Environ Sci Pollut Res, 23(22): 22906-22913, doi: $10.1007 / \mathrm{s} 11356-016-7511-6$

Banerjee G and Ray AK, 2017. The advancement of probiotics research and its application in fish farming industries. Res Vet Sci, 115: 66-77, doi: 10.1016/j.rvsc.2017.01.016

Bentzon-Tilia M, Sonnenschein EC and Gram L, 2016. Monitoring and managing microbes in aquaculture- towards a sustainable industry. Microb Biotechnol, 9(5): 576-584, doi: 10.1111/1751-7915.12392

Chu W, Zhou S, Zhu W and Zhuang X, 2014. Quorum quenching bacteria Bacillus sp. QSI-1 protect zebrafish (Danio rerio) from Aeromonas hydrophila infection. Sci Rep, 4(1): 5446, doi: $10.1038 / \mathrm{srep} 05446$

Dagar A, Zilberg D, Cohen Z, Boussiba S and KhozinGoldberg I, 2009. Short-term dietary supplementation with the microalga Parietochloris incisa enhances stress resistance in guppies Poecilia reticulata. Aquac Res, 41(2): 267-277, doi: 10.1111/j.13652109.2009.02329.x

Defoirdt T, Sorgeloos P and Bossier P, 2011. Alternatives to antibiotics for the control of bacterial disease in aquaculture. Curr Opin Microbiol, 14(3): 251-258, doi: 10.1016/ j.mib.2011.03.004

Dittmann KK, Rasmussen BB, Castex M, Gram L and Bentzon-Tilia M, 2017. The aquaculture microbiome at the centre of business creation. Microb Biotechnol, 10(6): 1279-1282, doi: 10.1111/1751-7915.12877

Elgeddawy SA, Shaheen HM, El-Sayed YS, Elaziz MA, Darwish A et al., 2020. Effects of the dietary inclusion of a probiotic or prebiotic on florfenicol pharmacokinetic profile in broiler chicken. J Anim Physiol Anim Nutr, 104(2): 549-557, doi: 10.1111/jpn.13317

FAO and WHO, 2001. Probiotics in food - health and 
nutrional properties and guidelines for evaluation. Food and Nutrition Paper 85, Rome

FAO/WHO (Food and Agriculture Organization of the United Nations/World Health Organization), 2006. Probiotics in food- health and nutritional properties and guidelines for evaluation. Food and Nutrition Paper 85, Rome

Faramarzi M, Kiaalvandi S and Iranshahi F, 2011. The effect of probiotics on growth performance and body composition of common carp (Cyprinus carpio). J Anim Vet Adv, 10(18): 2408-2413, doi: $10.3923 /$ java.2011.2408.2413

Fuller R, 1989. Probiotics in man and animals. J Appl Bacteriol, 66: 365-378

Gatesoupe FJ, 1999. Review: The use of probiotics in aquaculture. Aquaculture, 180(1-2): 147-165, doi: 10.1016/S0044-8486(99)00187-8

Gildberg A and Mikkelsen H, 1998. Effect of supplementing the feed of Atlantic cod (Gadus morhua) fry with lactic acid bacteria and immunostimulating peptides during a challenge trial with Vibrio anguillarum. Aquaculture, 167(1-2): 103-113, doi: 10.1016/S00448486(98)00296-8

Gobeli S, Goldschmidt-Clermont E, Frey J and Burr SE, 2009. Pseudomonas chlororaphis strain JF3835 reduces mortality of juvenile perch, Perca fluviatilis L., caused by Aeromonas sobria. J Fish Dis, 32(7): 597-602, doi: 10.1111/j.1365-2761.2009.01021.x

Gram L, Løvold T, Nielsen J, Melchiorsen J and Spanggaard B, 2001. In vitro antagonism of the probiont Pseudomonas fluorescens strain $\mathrm{AH} 2$ against Aeromonas salmonicida does not confer protection of salmon against furunculosis. Aquaculture, 199(1-2): 1-11, doi: 10.1016/S0044-8486(01)00565-8

Gram L, Melchiorsen J, Spanggaard B, Huber I and Nielsen TF, 1999. Inhibition of Vibrio anguillarum by Pseudomonas fluorescens $\mathrm{AH} 2$, a possible probiotic treatment of fish. Appl Environ Microbiol, 65: 969-973, doi: 10.1128/ AEM.65.3.969-973.1999

Hai NV and Fotedar R, 2009. Comparison of the effects of the prebiotics (Bio-Mos® and b-1,3-Dglucan) and the customised probiotics (Pseudomonas synxantha and $P$. aeruginosa) on the culture of juvenile western king prawns
(Penaeuslatisulcatus Kishinouye, 1896). Aquaculture, 289(3-4): 310-316, doi: 10.1016/ j.aquaculture. 2009.02.001

Hamid N, Baradaran A, Shirzad H and Rafieian-Kopaei M, 2014. New concepts in nutraceuticals as alternative for pharmaceuticals. Int J Prev Med, 5(12): 14871499

Hardy G, 2000. Nutraceuticals and functional foods: Introduction and meaning. Nutrition, 16(7-8): 688697, doi:10.1016/s 0899-007(00)00332-4

Hoseinifar SH, Sun YZ, Wang A and Zhou Z, 2018. Probiotics as means of diseases control in aquaculture, a review of current knowledge and future perspectives. Front Microbiol, 9: 2429, doi: 10.3389/fmicb.2018.02429

Kalatzis PG, Bastías R, Kokkari C and Katharios P, 2016. Isolation and characterization of two lytic bacteriophages, $\varphi \mathrm{St} 2$ and $\varphi \mathrm{Grn} 1$; phage therapy application for biological control of Vibrio alginolyticus in aquaculture live feeds. PLoS One, 11(3): e0151101, doi: 10.1371/ journal.pone. 0151101

Kesarcodi-Watson A, Miner P, Nicolas JL and Robert R, 2012. Protective effect of four potential probiotics against pathogen-challenge of the larvae of three bivalves: Pacific oyster (Crassostrea gigas), flat oyster (Ostrea edulis) and scallop (Pecten maximus). Aquaculture, 344-349: 29-34, doi: 10.1016/j.aquaculture. 2012.02.029

Kim JS, Harikrishnan R, Kim MC, Balasundaram C and Heo MS, 2010. Dietary administration of Zooshikella sp. to enhance the innate immune response and disease resistance of Paralichthys olivaceus against Streptococcus iniae. Fish Shellfish Immunol, 29(1): 104-110, doi: 10.1016/ j.fsi.2010.02.022

Kuebutornye FKA, Abarike ED, Lu Y, Hlordzi V, Sakyi ME et al., 2020. Mechanisms and the role of probiotic Bacillus in mitigating fish pathogens in aquaculture. Fish Physiol Biochem, 46(3): 819-841, doi: 10.1007/s10695-019-00754-y

Li P and Gatlin DMIII, 2004. Dietary brewer's yeast and the prebiotic Grobiotic ${ }^{\mathrm{TM}} \mathrm{AE}$ influence growth performance, immune responses and resistance of hybrid striped bass (Morone chrysops $\times$ M. saxatilis) to Streptococcus iniae infection. Aquaculture, 231(1-4): 445-456, doi: 10.1016/ j.aquaculture.2003.08.021 
Li X, Yu Y, Feng W, Yan Q and Gong Y, 2012. Host species as a strong determinant of the intestinal microbiota of fish larvae. J Microbiol, 50(1): 29-37, doi: 10.1007/s12275-012-1340-1

LópezNadal A, Ikeda-Ohtsubo W, Sipkema D, Peggs D, McGurk C et al., 2020. Feed, microbiota, and gut immunity: using the zebrafish model to understand fish health. Front Immunol, 11: 114, doi: 10.3389/fimmu. 2020.00114

Macey BM and Coyne VE, 2005. Improved growth rate and disease resistance in farmed Haliotis midae through probiotic treatment. Aquaculture, 245(1-4): 249-261, doi: 10.1016/ j.aquaculture.2004.11.031

Mahmoud HK, Reda FM, Alagawany M and Farag MR, 2021. Ameliorating deleterious effects of high stocking density on Oreochromis niloticus using natural and biological feed additives. Aquaculture, 531: 735900, doi: 10.1016/ j.aquaculture. 2020.735900

Marques A, Huynh T, Sorgeloos P and Bossier P, 2006. Use of microalgae and bacteria to enhance protection of gnotobiotic Artemia against different pathogens. Aquaculture, 258 (1-4): 116-126, doi:10.1016/j.aquaculture. 2006.04.021

Mohanty SN, Swain SK and Tripathi SD, 1996. Rearing of catla (Catla catla Ham.) spawn on formulated diets. J Aquac Trop, 11: 253-258

Moriarty DJW, 1998. Control of luminous Vibrio species in penaeid aquaculture ponds. Aquaculture, 164(1-4): 351-358, doi: 10.1016/ S0044-8486(98)00199-9

Naiel MAE, Farag MR, Gewida AGA, Elnakeeb M, Amer MS et al., 2020a. Using lactic acid bacteria as an immunostimulants in cultured shrimp with special reference to Lactobacillus spp. Aquac Int, 71, doi: 10.1007/s10499-02000620-2

Naiel MAE, Alagawany M, Patra AK, El-Kholy AI, Amer MS et al., 2020b. Beneficial impacts and health benefits of macroalgae phenolic molecules on fish production. Aquaculture, 736186, doi: 10.1016/j.aquaculture. 2020.736186

Nikoskelainen S, Ouwehand AC, Bylund G, Salminen $\mathrm{S}$ and Lilius EM, 2003. Immune enhancement in rainbow trout (Oncorhynchus mykiss) by potential probiotic bacteria (Lactobacillus rhamnosus). Fish Shellfish Immunol, 15(5): 443-452, doi: 10.1016/S1050-4648(03) 00023-8

Niu Y, Defoirdt T, Baruah K, de Wiele TV, Dong S et al., 2014. Bacillus sp. LT3 improves the survival of gnotobiotic brine shrimp (Artemia franciscana) larvae challenged with Vibrio campbellii by enhancing the innate immune response and by decreasing the activity of shrimp-associated vibrios. Vet Microbiol, 173(34): 279-288, doi: 10.1016/j.vetmic. 2014.08.007

Noor Z, Noor M, Khan I and Khan SA, 2020. Evaluating the lucrative role of probiotics in the aquaculture using microscopic and biochemical techniques. Microsc Res Tech, 83(3): 310-317, doi: 10.1002/jemt.23416

Pan X, Wu T, Zhang L, Song Z, Tang H et al., 2008. In vitro evaluation on adherence and antimicrobial properties of a candidate probiotic Clostridium butyricum CB2 for farmed fish. J Appl Microbiol, 105: 1623-1629

Park SC, Shimamura I, Fukunaga M, Mori K and Nakai $\mathrm{T}, 2000$. Isolation of bacteriophages specific to a fish pathogen, Pseudomonas plecoglossicida, as a candidate for disease control. Appl Environ Microbiol, 66(4): 1416-1422, doi: 10.1128/ aem.66.4.1416-1422.2000

Picchietti S, Mazzini M, Taddei AR, Renna R, Fausto AM et al., 2007. Effects of administration of probiotic strains on GALT of larval gilthead seabream: immunohistochemical and ultrastructural studies. Fish Shellfish Immunol, 22(1-2): 57-67, doi: 10.1016/j.fsi.2006.03.009

Porsby CH and Gram L, 2016. Phaeobacter inhibens as biocontrol agent against Vibrio vulnificus in oyster models. Food Microbiol, 57: 63-70, doi: 10.1016/j.fm.2016.01.005

Preetha R, Jayaprakash NS and Singh B, 2007. Synechocystis MCCB 114 and 115 as putative probionts for Penaeus monodon post-larvae. Dis Aquat Org, 74(3): 243-247, doi: 10.3354/ dao074243

Rico A, Oliveira R, Mcdonough S, Matser A, Khatikarn J et al., 2014. Use, fate and ecological risks of antibiotics applied in tilapia cage farming in Thailand. Environ Pollut, 191: 8-16, doi: 10.1016/j.envpol.2014.04.002 
Ring $\varnothing$ E, 2020. Probiotics in shellfish aquaculture. Aquac Fish, 5(1): 1-27, doi: 10.1016/ j.aaf.2019.12.001

Schmidt V, Gomez-Chiarri M, Roy C, Smith K and Amaral-Zettler L, 2017. Subtle microbiome manipulation using probiotics reduces antibiotic-associated mortality in fish. mSystems, 2(6): e00133-17, doi: 10.1128/ mSystems.00133-17

Scholz U, Diaz GG, Ricque D, Suarez LEC, Albores FV et al., 1999. Enhancement of vibriosis resistance in juvenile Penaeus vannamei by supplementation of diets with different yeast products. Aquaculture, 176(3-4): 271-283, doi: $10.1016 / \mathrm{S} 0044-8486(99) 00030-7$

Sharif M, Zafar MH, Aqib AI, Saeed M, Farag MR et al., 2021. Single cell protein: sources, mechanism of production, nutritional value and its uses in aquaculture nutrition. Aquaculture, 531: 735885 , doi: 10.1016/j.aquaculture. 2 020.735885

Soliman WS, Shaapan RM, Mohamed LA and Gayed SSR, 2019. Recent biocontrol measures for fish bacterial diseases, in particular to probiotics, bio-encapsulated vaccines, and phage therapy. Open Vet J, 9(3): 190-195, doi: 10.4314/ovj.v9i3.2

Soomro RN, Abd El-Hack ME, Shah SS, Taha AE, Alagawany $\mathrm{M}$ et al., 2019. Impact of restricting feed and probiotic supplementation on growth performance, mortality and carcass traits of meattype quails. Anim Sci J, 90(10): 1388-1395, doi: 10.1111/asj.13290

Supamattaya K, Kiriratnikom S, Boonyaratpalin M and Borowitzka L, 2005. Effect of a Dunaliella extract on growth performance, health condition, immune response and disease resistance in black tiger shrimp (Penaeus monodon). Aquaculture, 248(1): 207-216, doi: 10.1016/j.aquaculture. 2005.04.014

Talpur AD, Memon AJ, Khan MI, Ikhwanuddin M, Daniel MM et al., 2012. Inhibition of pathogens by lactic acid bacteria and application as water additive multi isolates in early stages larviculture of $P$. pelagicus (Linnaeus, 1758). J Anim Plant Sci, 22(1): 54-64

Taoka Y, Maeda H, Jo J, Jeon MJ, Bai SC et al., 2006a. Growth, stress tolerance and non-specific immune response of Japanese flounder
Paralichthys olivaceus to probiotics in a closed recirculating system. Fish Sci, 72(2): 310-321, doi: 10.1111/j.1444-2906.2006.01152.x

Taoka Y, Maeda H, Jo JY, Kim SM, Park SI et al., 2006b. Use of live and dead probiotic cells in tilapia Oreochromis niloticus. Fish Sci, 72(4): 755766, doi: 10.1111/j.1444-2906.2006.01215.x

Tapia-Paniagua ST, Vidal S, Lobo C, Prieto-Álamo MJ, Jurado J et al., 2014. The treatment with the probiotic Shewanella putrefaciens Pdp11 of specimens of Solea senegalensis exposed to high stocking densities to enhance their resistance to disease. Fish Shellfish Immunol, 41(2): 209-221, doi: 10.1016/j.fsi.2014.08.019

Tarnecki AM, Wafapoor M, Phillips RN and Rhody NR, 2019. Benefits of a Bacillus probiotic to larval fish survival and transport stress resistance. Sci Rep, 9(1): 4892, doi: 10.1038/ s41598-019-39316-w

Tovar D, Zambonino J, Cahu C, Gatesoupe FJ, Vazquez-Juarez R et al., 2002. Effect of yeast incorporation in compound diet on digestive enzyme activity in sea bass (Dicentrarchus labrax) larvae. Aquaculture, 204(1-2): 113-123, doi: 10.1016/S0044-8486(01)00650-0

Tseng DY, Ho PL, Huang SY, Cheng SC, Shiu YL et al., 2009. Enhancement of immunity and disease resistance in the white shrimp, Litopenaeus vannamei, by the probiotic, Bacillus subtilis E20. Fish Shellfish Immunol, 26(2): 339-344, doi: 10.1016/j.fsi.2008.12.003

Wang A, Ran C, Wang Y, Zhang Z, Ding Q et al., 2019. Use of probiotics in aquaculture of China-A review of the past decade. Fish Shellfish Immunol, 86: 734-755, doi: 10.1016/ j.fsi.2018.12.026

Żczek M, Weber-D ${ }^{1}$ browska B and Górski A, 2020. Phages as a cohesive prophylactic and therapeutic approach in aquaculture systems. Antibiotics (Basel), 9(9): 564, doi: 10.3390/antibiotics9090564

Zorriehzahra MJ, Delshad ST, Adel M, Tiwari R, Karthik $\mathrm{K}$ et al., 2016. Probiotics as beneficial microbes in aquaculture: an update on their multiple modes of action: A review. Vet Q, 36(4): 228-241, doi: $10.1080 / 01652176.2016 .1172132$ 